\title{
Malignant Odontogenic Neoplasm
}

National Cancer Institute

\section{Source}

National Cancer Institute. Malignant Odontogenic Neoplasm. NCI Thesaurus. Code C4812.

A rare neoplasm arising from tooth-forming tissues. It occurs in the maxillofacial skeleton or the gingiva. Symptoms include swelling, pain, bleeding, mobility of affected teeth, and oral mucosa ulcerations. It may metastasize to lymph nodes and distant anatomic sites early. 